\title{
INFLUENCE OF GLUING TECHNOLOGY ON THE SHEAR STRENGTH IN THE GLUING OF SOLID WOOD
}

\author{
Murco Obucina ${ }^{\mathrm{a}}$, Almir Akvic ${ }^{\mathrm{b}}$ \\ ${ }^{a}$ Faculty of Mechanical Engineering, University of Sarajevo, V. setaliste 9, Sarajevo 71000, Bosnia and Herzegovina \\ ${ }^{b}$ Company “AL-EX”, Sarajevska 135, Zenica 72000, Bosnia and Herzegovina
}

\begin{abstract}
In wood industry are applied cold, warm and HF (high frequency) technologies. The essential difference of the bonding process is in the method of heating the material, the temperature gradient, the gradient moisture and bonding time. This paper considers the impact of technological process applied to the bonding strength of solid beech panels with PVAc glue.Each bonding process has been done by 30 samples for testing shear strength of the glued joint. The results were statistically analysed and compared with each other using the Student's t-Test. It was established that the technological process of gluing influence the shear strength. Shear strength by cold gluing was found to be significant different to the other two methods, indicating that gradients of temperature and humidity in the zone the glued joint and the length of time gluing significantly affect the gluing strength.
\end{abstract}

Keywords: technology wood gluing; shear strength; statistical analysis; moisture gradient; temperature gradient
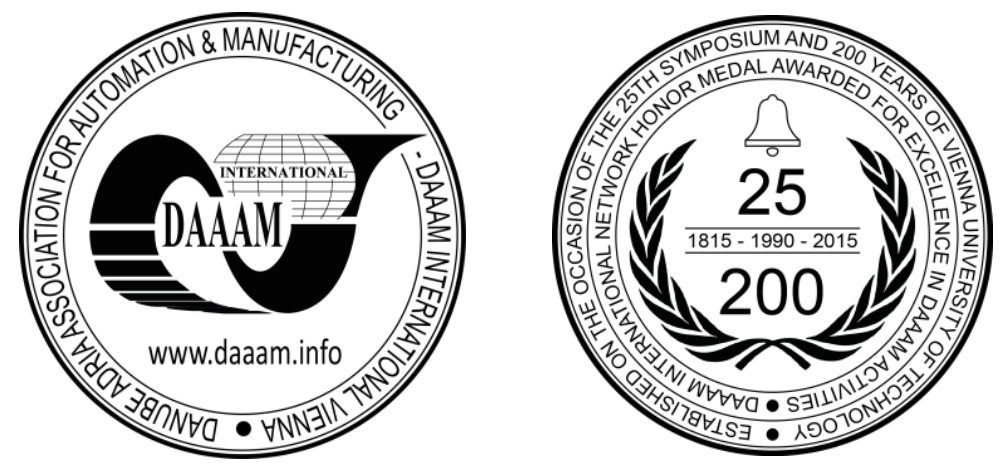

This Publication has to be referred as: Obucina, M[urco] \& Akvic, A[lmir] (2016). Influence of Gluing Technology on the Shear Strength in the Gluing of Solid Wood, Proceedings of the 26th DAAAM International Symposium, pp.0189-0195, B. Katalinic (Ed.), Published by DAAAM International, ISBN 978-3-902734-07-5, ISSN 1726-9679, Vienna, Austria DOI:10.2507/26th.daaam.proceedings.026 


\section{Introduction}

The movement of the adhesive in forming the bonded joint is observed from the time of applying the adhesive to the formation of tight compound. The adhesive is generally applied only to one surface of which will enter the process of bonding, while the glue passes through the following stages [3]:

- Spreading the adhesive over the surface,

- Transfer of adhesive on one surface of the other,

- Penetration of adhesive in the wood,

- $\quad$ Surface wetting and

- Creating a solid film.

Quality is the most significant in industrial wood production, but bonding speed is also very important parameter. Bonding speed significantly affects the overall production efficiency (reduction of production space and equipment for bonding) and a significant flow of production.

Speeding up the gluing process can be achieved by accelerating the removal of the liquid components of the glue and accelerate the process of a chemical reaction. There are two possibilities to achieve this:

- Adding hardener that accelerates a chemical reaction of curing adhesive

- Increasing temperature in the area of joints, resulting in acceleration process of removing fluid and chemical reactions in the adhesive.

In accordance with technological and organizational requirements, depending on object of gluing or which adhesive and what equipment is available, gluing can be:

- The cold, without bringing heat and

- With heating, the supply of heat.

Both procedures have their advantages and disadvantages [4]. The cold gluing largely slows the flow of production. However, the cold gluing is used for many products in industrial production, because otherwise it is not possible or is irrational. This method of bonding is an extremely cost-effective and does not require large space or investments.

Microscopy and roughness measurements showed significant differences between the bonding surfaces, notably with regard to cell damage and the level of fibrillation. The surface texture had significant impact on shear and delimitation results. While shear tests showed good bond performance when tested in dry condition, moisture treatment revealed differences between surfaces, in particular with regard to wood failure. [2].

Rowell [6] found that the strength of the bonded joint depends on several factors, the most on the adhesion, in addition to the properties of the adhesive. The adhesion of the glue-wood primarily depends on the wetting surface, glue penetration, porosity, $\mathrm{pH}$ value, moisture, surface tension, surface condition and anatomical directions of wood.

Anatomical and physical properties of wood that is glued, proper working conditions (relative humidity and temperature), the quality of surface treatment and joints, the pressure of the pressing etc, are in addition to these phases, very important factors that influence on the effectiveness of bonding.

Obucina at all [5] examined the impact of adhesive technologies (convection and VF gluing) to the relevant physical and mechanical properties of LVL, based on beech veneer. In addition, it was investigated crawl under constant load, and a high content of humidity.

Gluing temperature is very important for the overall process and significantly affects the quality of gluing. The duration of gluing depends on the temperature of gluing and the applied technological procedure. Explained it as better overflow of adhesive at high oven temperatures due to reduction of viscosity, resulting in improved penetration of adhesives in wood [1].

VF bonding adhesive is heated very quickly. This results in a rapid and significant reduction in viscosity. The adhesive is in this state more uniformly distributed over the glued joint and hardens quickly, but less penetrates into the wood. Uniform humidity and temperature throughout the cross section is balanced, which gives the compound without excessive internal tensions.

The main purpose is to explore the impact of technological process of gluing on bonding strength of beech wood, which is most commonly used for production of solid wood furniture. Different technologies have different gluing modes, causing different gradients of moisture, temperature and tension in the glue joints.

\section{Research methods}

The study used standard methods in real production conditions. In addition, special attention was paid to the same method of sample preparation, from the first to the last step, so as to have minimal or no dissipation of value in the final results. 
The process of preparing materials for experiments can be summed up in a few steps:

- Cutting the dried boards in elements.

- Preparation of wood surfaces for bonding was performed on two different types of planer.

- Gluing lamella in the boards: cold press, warm press or high frequency (HF) press

- Sanding boards on sanding machine.

- Cutting board on experimental samples.

It is important to emphasize that all operations are carried out under the same climatic conditions (temperature $20{ }^{\circ} \mathrm{C}$ and relative humidity $55-65 \%$ ).

In the wood industry of solid wood, it is almost impossible to imagine the production of any product with out planning. Planning is considered the first phase of finalization of the product. The main task of planers for further processing flow provide the correct geometry of the element and ensure adequate surface roughness. Preparation of wood surfaces for bonding was performed on two different types of planer, classic planer and fig machine (sawing), type WEINIG Unimat Super 4. Planning is done at the feed speed from $15 \mathrm{~m} / \mathrm{min}$ at $6000 \mathrm{r} / \mathrm{min}$, with a knife rake angle of $15^{\circ}$. During the removing, chip thickness was $2 \mathrm{~mm}$ on all four sides in one pass. The biggest disadvantage of surface preparation on the classic planer are cycloid, kinematic irregularities which occur as a result of the circular movement of the tool (main movement) and rectilinear movement of the work-piece (subsidiary motion) (Fig. 1a). The second group was planed on the plane Unimat Super 4 (Fig.1.b).

a

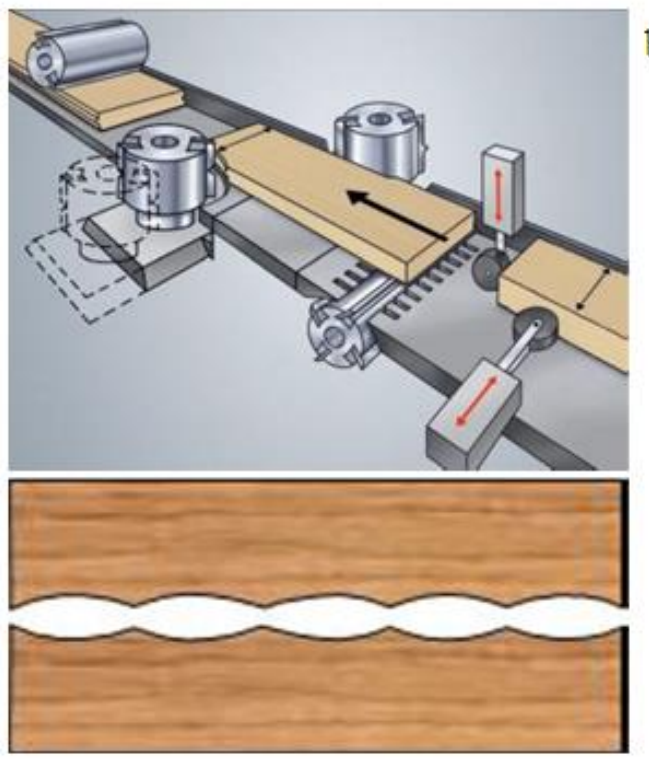

b
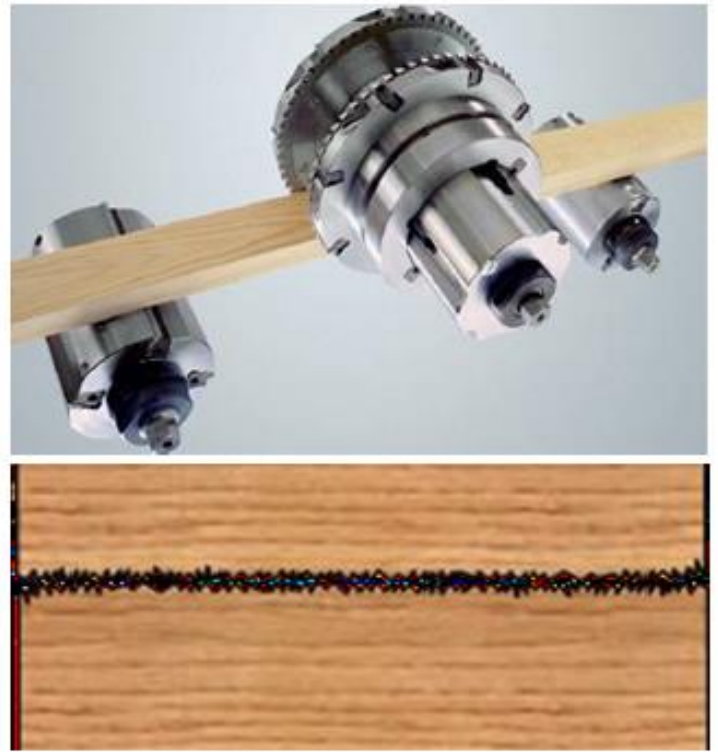

Fig. 1. Schematic representation of processing and position the tool head and surface profile (a) classic planning (b) planning with WEINIG Unimat Super 4

To measure the surface roughness an Electrotechnical profilmeter MitotuyoSJ-201, was used (Fig. 2). With Mitutoyo device, mean deviation of profile ( $\mathrm{Ra}$ ) is measured, which represents the arithmetic mean value of the distances of all points of the effective profile of the central line.

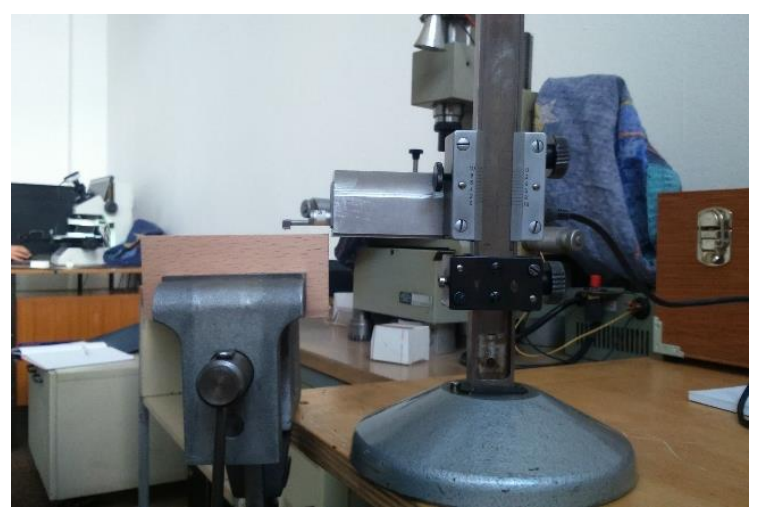

Fig. 2. Measurement of roughness probe after planning 
The process of contact (pressing) was made on the following presses:

- Cold press

- Hot press

- VF press

Each of these presses was used for gluing 10 panel composed of 3 lamells. Dimensions lamells were 950x50x21 mm, while the final dimensions of the board amounted to 950x150x19 mm. In this way, bonding is a total of 30 solid panels.

\subsection{Pressing process}

After applying the glue on adhesion surface,the blades were placed on a cold press type "SLV-100-H" (Figure 3a). Cold presses of this type has side presser 12 (hydraulic cylinders) and the presser on a massive plate operate across the face or reverse the panel. Specific pressure was $0.8 \mathrm{~N} / \mathrm{mm}^{2}$, and the amount of glue $220 \mathrm{~g} / \mathrm{m}^{2}$. Gluing temperature is actually the temperature of the hall and was at $20{ }^{\circ} \mathrm{C}$. The optimum time on a cold press for board and glue these characteristics is 30-40 min. In this study, duration was set to 35 minutes.

Unlike cold press where the gluing is performed at a temperature of $20{ }^{\circ} \mathrm{C}$, the hot press is used for heat conduction in order to accelerate the gluing process. Measured temperature in the contact plates amounted $60{ }^{\circ} \mathrm{C}$, the specific pressure of $0.7 \mathrm{~N} / \mathrm{mm}^{2}$, the amount of glue $220 \mathrm{~g} / \mathrm{m}^{2}$, while the bonding time lasted 6 minutes (Figure 3.b).

For HF gluing it was used "ProfiPress II", by producer "Weinig" (Figure 3.c). This press type has goal to shorten bonding time. HF generators, for heat emission to wood, enabled significantly shortening the time of gluing. Specific pressure was $1.4 \mathrm{~N} / \mathrm{mm}^{2}$, the amount of glue $120 \mathrm{~g} / \mathrm{m}^{2}$, and bonding time 2.5 minutes.
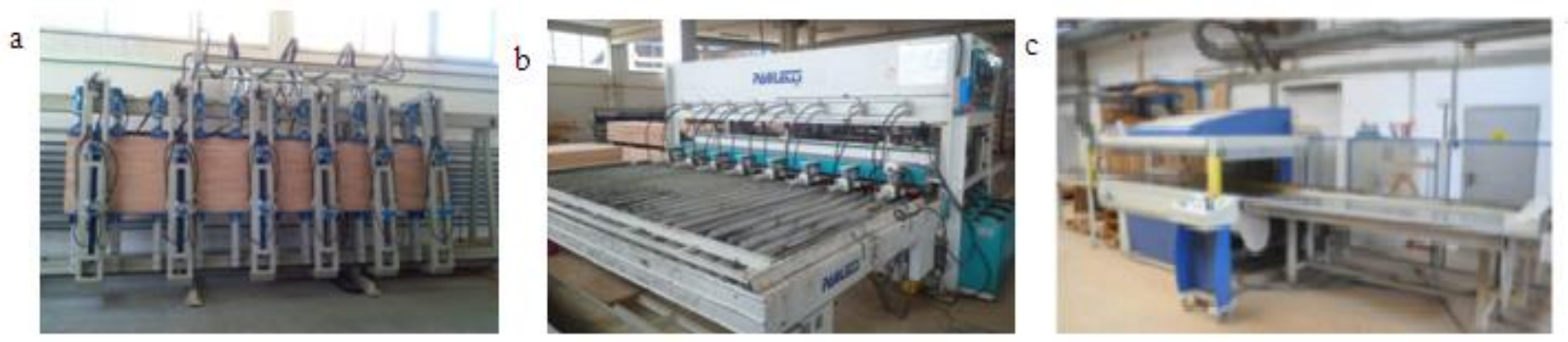

Fig. 3.Pressing process a) Gluing on the cold press; b)Gluing with warm press; c) HF press gluing

When gluing and period of relaxation are completed, it is necessary to make sanding to a specific thickness. All boards are sanded to a thickness of $19.05 \mathrm{~mm}$. Then, from sadned panels, were cut tubes for testing shear strength according to CEN / TS 13354.

The next step was breaking tubes on specialized machine ,Zwick“, in climatic conditions of temperature 18.9 ${ }^{\circ} \mathrm{C}$ and relative humidity $62 \%$. Speed shift load was $10 \mathrm{~mm} / \mathrm{min}$, and the reading of results was in range up to $15 \mathrm{kN}$

Testing was conducted on a total of 210 shear surface. Based on the values of load and measured values of the thickness and width of the shear surface there were calculated shear strength values.

\section{Results}

For each of the tests were done individual Student t-Test and results became statistically valid. This type of statistical data processing (t-Test) is used in order to give an answer to the question of whether there is a possibility that the two samples come from the same two basic population, with equal arithmetic means.

Upon testing of surface roughness was completed it was carried out to collect and process the results. For data processing was used " Microsoft Excel" and the results are displayed graphically on Figure 4. 

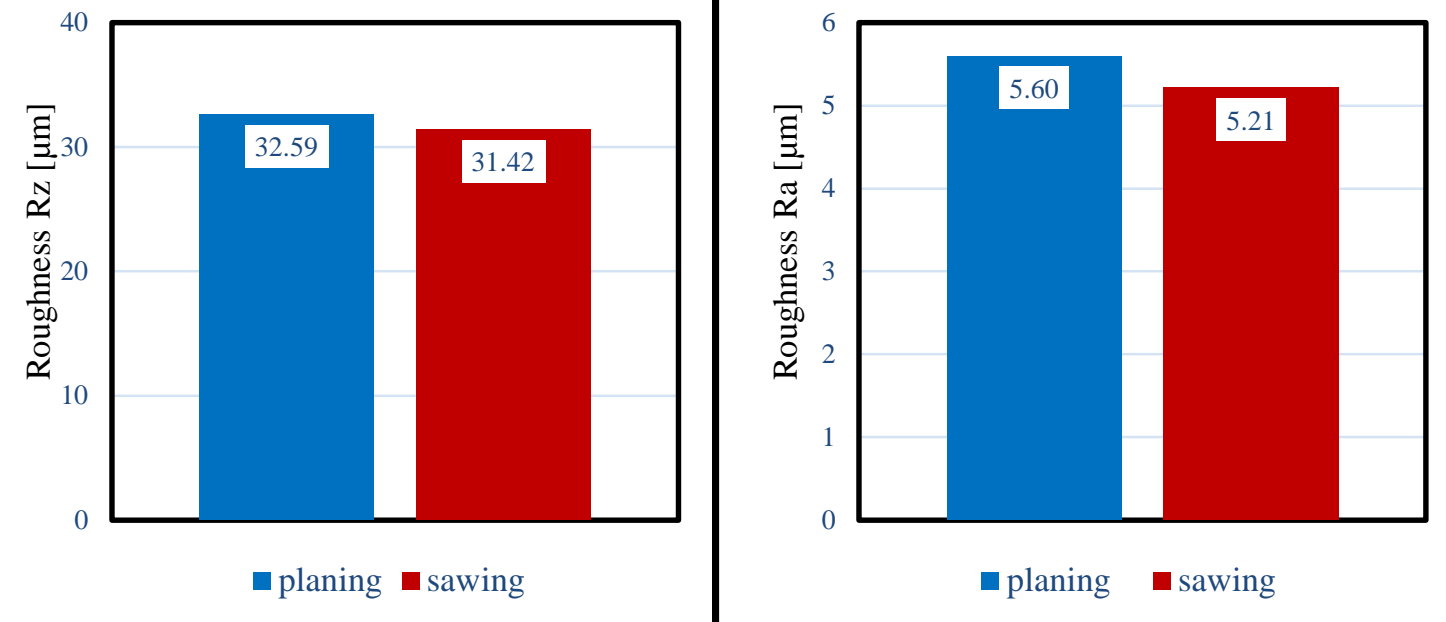

Fig. 4. Rougness data „Ra“ and „Rz“for planing and sawing method of surface preparation

Results.of t-Test are presented in the tables 1 and 2.

\begin{tabular}{lll}
\hline Alpha & 0,05 & 0,01 \\
\hline $\mathrm{t}$ Stat & \multicolumn{2}{c}{0,28047} \\
t Critical two-tail & 2,10092 & 2,87844 \\
t Stat and t Critical two-tail compare & $\mathrm{t}<\mathrm{tg}$ & $\mathrm{t}<\mathrm{tg}$ \\
Conclusion & $\mathrm{H}_{0}$ & $\mathrm{H}_{0}$ \\
\hline
\end{tabular}

Table 1. t-Test Two-Sample Assuming Equal Variances for roughness Ra

According to data from the table 1 we can see by comparing the values of mean deviation of the profile (Ra) of two different sets of data (processing by planning and sawing) for different levels of significance, it is adopted the null hypothesis. There is no significant difference between the observed variables.

\begin{tabular}{lll}
\hline Alpha & 0,05 & 0,01 \\
\hline $\mathrm{t}$ Stat & \multicolumn{2}{c}{0,13896} \\
$\mathrm{t}$ Critical two-tail & 2,10092 & 2,87844 \\
$\mathrm{t}$ Stat and t Critical two-tail compare & $\mathrm{t}<\mathrm{tg}$ & $\mathrm{t}<\mathrm{tg}$ \\
Conclusion & $\mathrm{H}_{0}$ & $\mathrm{H}_{0}$ \\
\hline
\end{tabular}

Table 2. t-Test Two-Sample Assuming Equal Variances for roughness Rz

According to data from the table 2 we can see by comparing the values of mean deviation of the profile (Ra) of two different sets of data (processing by planning and sawing) for different levels of significance, it is adopted the null hypothesis. There is no significant difference between the observed variables.

\subsection{Shear strength in the dry state}

In phase 1 an analysis and comparison of the results that had different pre-treated area has been done. The results are shown in Table 3 and in Figure 5.

\begin{tabular}{rccc}
\hline & \multicolumn{3}{c}{ Shear strength [MPa] } \\
\hline & HF press & Cold press & Warm press \\
\cline { 2 - 4 } Planing & 12,11 & 13,48 & 14,86 \\
Sawing (W_S4) & 14,09 & 14,80 & 14,36 \\
\hline
\end{tabular}

Table 3. Results of shear strength in dry state 


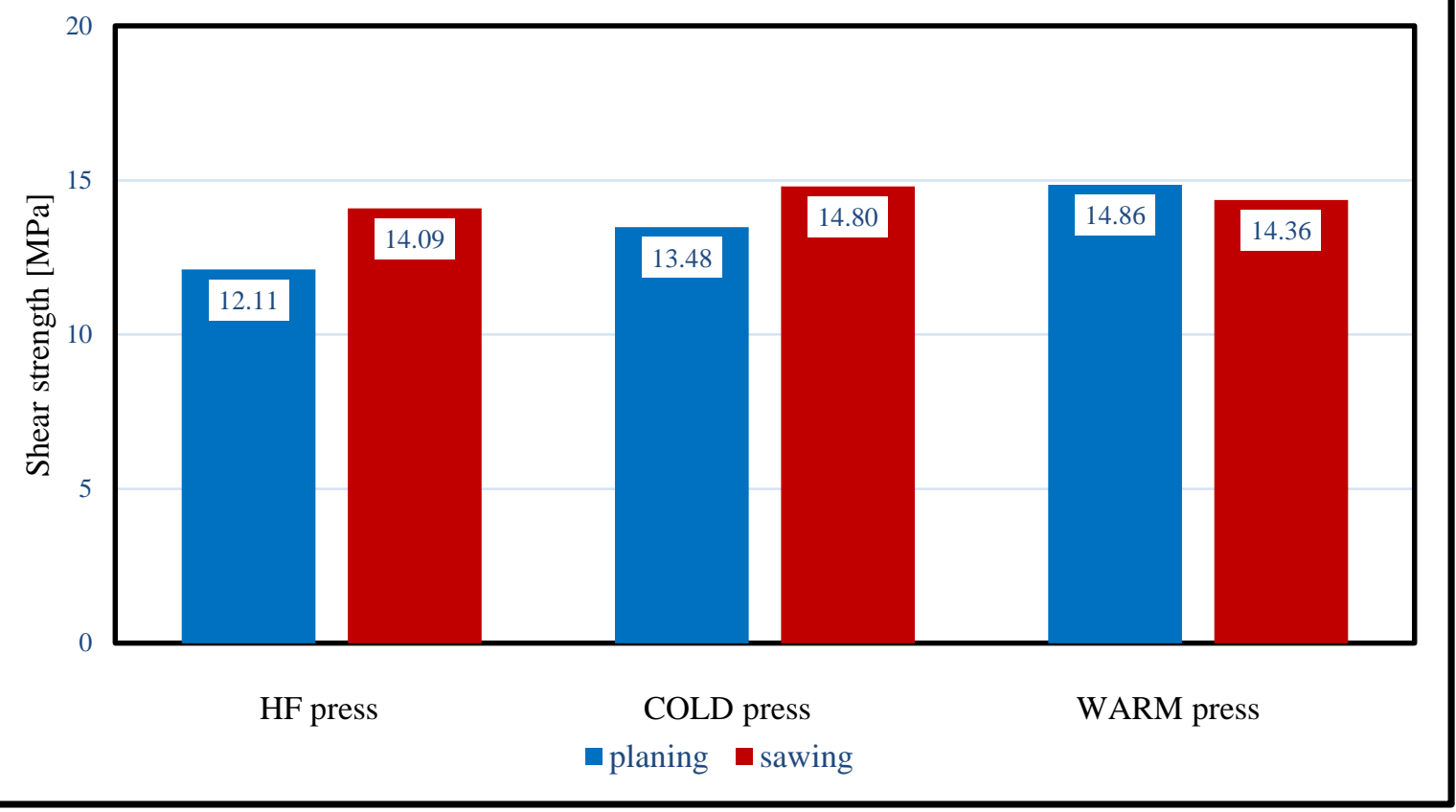

Fig. 5. Shear strength of differently prepared surfaces

\begin{tabular}{lcccc}
\hline & \multicolumn{2}{c}{ HF/Cold } & \multicolumn{2}{c}{ HF/Warm } \\
\hline Alpha & 0,05 & 0,01 & 0,05 & 0,01 \\
t Stat & \multicolumn{2}{c}{$-3,29356$} & \multicolumn{2}{c}{$-8,58390$} \\
t Critical two-tail & 2,01063 & 2,68220 & 2,01063 & 2,68220 \\
t Stat and t Critical two-tail compare & $|\mathrm{t}|>\operatorname{tg}$ & $|\mathrm{t}|>\operatorname{tg}$ & $|\mathrm{t}|>\operatorname{tg}$ & $|\mathrm{t}|>\operatorname{tg}$ \\
Conclusion & $\mathrm{H}_{1}$ & $\mathrm{H}_{1}$ & $\mathrm{H}_{1}$ & $\mathrm{H}_{1}$ \\
\hline
\end{tabular}

Table 4. t-Test Two-Sample Assuming Equal Variances for different types of presses with planning bonding surface preparation

According to data from the table 4 we can see by comparing the values of mean deviation of the shear strength for tubes prepared by planning and bonded with 2 combinations (HF and COLD; HF and WARM presses)for different levels of significance, it is rejected the null hypothesis. There are significant and highly significant differences between the observed variables.

\begin{tabular}{lcccc}
\hline & \multicolumn{2}{c}{ HF/Cold } & \multicolumn{2}{c}{ HF/Warm } \\
\hline Alpha & 0,05 & 0,01 & 0,05 & 0,01 \\
t Stat & \multicolumn{2}{c}{$-3,05073$} & \multicolumn{2}{c}{$-1,07384$} \\
t Critical two-tail & 2,01063 & 2,68220 & 2,01063 & 2,68220 \\
t Stat and t Critical two-tail compare & $|t|>\operatorname{tg}$ & $|t|>\operatorname{tg}$ & $|t|<\operatorname{tg}$ & $|t|<\operatorname{tg}$ \\
Conclusion & $\mathrm{H}_{1}$ & $\mathrm{H}_{1}$ & $\mathrm{H}_{0}$ & $\mathrm{H}_{0}$ \\
\hline
\end{tabular}

Table 5. t-Test Two-Sample Assuming Equal Variances for different types of presses with sawing bonding surface preparation

According to data from the table 5 we can see by comparing the values of mean deviation of the shear strength for tubes prepared by sawing and bonded with HF and Cold press for different levels of significance, it is rejected the null hypothesis. There are significant and highly significant differences between the observed variables.

According to data from the table 5 we can also see, by comparing the values of mean deviation of the shear strength for tubes prepared by sawing and bonded with HF and Warm press for different levels of significance, it is adopted the null hypothesis. There is no significant difference between the observed variables. 
This paper analyzes the Impact technological process on the quality of bonding solid beech panels. Surface preparation for bonding was carried out by planning the classic planers and sawing on special planers "Weinig S4". Using the device "Mitotuyo SJ-201" for measuring roughness was measured roughness for each procedure planning.

Bonding samples was performed by a standard cold and warm presses and press with high-frequency generator. All procedures were carried in the same climatic conditions.

Testing of shear strength was done using the standard "EN 392: 1995" and "EN 204". Shear strength is determined for each procedure planning by 60 sample ( 20 samples for each technological process of gluing).

In future research it is necessary to analyze the internal tensions in the glue joints and the impact of moisture and temperature gradients on the strength and durability of bonded joint. Also, it is necessary to analyze the impact of other parameters regime bonding. Examination presented in this paper should be repeated for a number of other wood thicknesses.

\section{Conclusion}

In this paper analyzed influence of three different technological process of gluing the bonding quality solid beech. It was established that the technological process of gluing influence the shear strength. Based on these analyzes and the results obtained can be defined by the following conclusions:

- There were no significant differences in surface roughness obtained by conventional planning and fig machine (sawing), although the processing of these two machines results different types of surfaces. Roughness is slightly higher planning processing.

- The results of shear strength have shown that there is a highly significant difference in shear strength depending on the technological process of gluing, previously processed by planning. In special planning (sawing) processing highly significant difference was observed only in comparison to the shear strength samples glued on HF and cold presses. It should be taken into account that only $2 \%$ of total gluing surface (150 samples) was determined on hardened glue. Accommodate the largest number of cracks at the adhesive was recorded in the combination planning surface preparation and gluing on a warm press (crack of $7.8 \%$ ).

- The results suggest that the technological process of bonding and surface preparation of wood affects the quality of the shear strength, especially on the consistent quality of glued joint.

During preparation of this experiment would be unrealistic to exclude other factors that impact on the quality of bonding, such as anatomy, physical and mechanical wood properties, then the influence of the pressure, which was slightly different depending on the types of presses, and the open time bonding. Examination presented in this paper should be repeated for a number of other wood thicknesses.

\section{References}

[1] Bradly D. E., Kamke F.A.8. Efect of hot-presing parameters on resin penetracion. Forest Production Journal, 38, 11(1998)63-68.

[2] Knorz, M., Neuhaeuser, E., Torno, S., Kuilen, J. W. Influence of surface preparation methods on moisture-related performance of structural hardwood-adhesive bonds. International Journal of Adhesion \& Adhesives 57 (2015) $40-48$.

[3] Marra, A.A. Technology of wood bonding: principles in practice, Van Nostrand Reinhold, New York. 1992.

[4] Obucina, M.; Gondzic, E., Manso, E. The Influence of Adhesion Temperature to the Shear Strength of Width Glued Wooden Elements ". 25th DAAAM International Symposium on Intelligent Manufacturing and Automation, 2014, Procedia Engineering, Volume 100, 2015, p 321-327.

[5] Obucina M., Dzaferovic E., Bajramovic R., Resnik J.. Influence of gluing technology on viscoelasticity properties of LVL. Wood Research. 51 (4): (2006) 11- 22.

[6] I. Rowell, R, M. Chemical Modificatio of Wood for Improved adhesion in Composites. Wod Adhesives. Forest Products Society, Madison, (1996) WI., 69-78. 